\title{
AVALIAÇÁO DA CULTURA DE SEGURANÇA DO PACIENTE EM UM HOSPITAL DO SUL DO BRASIL
}

\author{
EVALUATION OF PATIENT SAFETY CULTURE IN A HOSPITAL IN \\ SOUTHERN BRAZIL
}

\section{EVALUACIÓN DE LA CULTURA DE SEGURIDAD DEL PACIENTE EN UN HOSPITAL DEL SUR DE BRASIL}

\author{
Aline Massaroli* \\ Maria Eduarda De Carli Rodrigues** \\ Karine KoOKE*** \\ Érica De Brito Pitilin**** \\ FABIANA Brum HaAG***** \\ Jeferson Santos Araújo******
}

\begin{abstract}
RESUMO
Objetivo: Avaliar o nível de cultura de segurança do paciente, na perspectiva dos profissionais de saúde, em um hospital do sul do Brasil. Material e Método: Estudo quantitativo aplicado pelo instrumento Hospital Survey on Patient Safety Culture (HOSPSC), de maio a junho de 2018; a amostra de 291 participantes foi obtida por conveniência, os dados foram organizados no programa Microsoft Excel ${ }^{\oplus}$. Para a análise e interpretação das dimensóes da cultura de segurança, foi aplicada a metodologia proposta pela Agency Healthcare Research and Quality (AHRQ). Resultados: O percentual geral de respostas positivas foi de 46\%, a dimensão com maior percentual de respostas positivas foi "aprendizagem organizacional e melhoria contínua"; nenhuma dimensão atingiu um valor superior a 75\%; a dimensão que apresentou maior fragilidade foi "resposta não punitiva ao
\end{abstract}

*Enfermeira, Doutora em Enfermagem, Curso de Graduação em Enfermagem, Universidade Federal da Fronteira Sul, Chapecó, Santa Catarina, Brasil. ORCID: https://orcid.org/0000-0003-4779-5579 E-mail: alinemassaroli@gmail.com Autor correspondente.

**Enfermeira. Curso de Graduação em Enfermagem, Universidade Federal da Fronteira Sul, Chapecó, Brasil. ORCID: https:// orcid.org/0000-0001-5623-7718 E-mail: maria.carli@uffs.edu.br Autor Correspondente.

${ }^{* * *}$ Enfermeira. Secretaria Municipal de Saúde, Chapecó, Santa Catarina, Brasil. ORCID: https://orcid.org/0000-0001-74412073 E-mail: karine.kooke@hotmail.com

****Enfermeira, Doutora em Ciências da Saúde. Curso de Graduação em Enfermagem, Universidade Federal da Fronteira Sul, Chapecó, Santa Catarina, Brasil. ORCID: https://orcid.org/0000-0003-3950-2633 E-mail: erica.pitilin@uffs.edu.br

*****Enfermeira, Doutora em Ciências da Saúde, Curso de Graduação em Enfermagem, Universidade Federal da Fronteira Sul, Chapecó, Santa Catarina, Brasil. ORCID: https://orcid.org/0000-0002-1358-766X E-mail: fabiana.haag@uffs.edu.br

******Enfermeiro, Doutor em Enfermagem. Curso de Graduação em Enfermagem, Universidade Federal da Fronteira Sul, Chapecó, Santa Catarina, Brasil. ORCID: https://orcid.org/0000-0003-3311-8446 E-mail: jeferson.araujo@uffs.edu.br 
erro", com menor percentual de respostas positivas (16\%); a maioria dos profissionais (56\%) não fez nenhuma notificaçáo no período de 12 meses; em relação à percepção dos participantes sobre a segurança do paciente em sua unidade de trabalho, foi observada quantidade semelhante entre aqueles que têm percepção positiva (muito boa e excelente) e negativa (regular, ruim e péssima). Conclusóes: Há fragilidades na cultura de segurança do paciente, evidenciando a necessidade de se discutir o tema em todas as áreas de atenção da instituição.

Palavra-chave: Segurança do paciente. Cultura de Segurança. Serviços de saúde. Avaliação. Qualidade da assistência.

\begin{abstract}
Objective: To assess the level of patient safety culture, from the perspective of health professionals, in a hospital in southern Brazil. Material and Method: Quantitative study carried out using the Hospital Survey on Patient Safety Culture instrument, from May to June 2018. The sample was drawn using convenience sampling and consisted of 291 participants; data were organized in Microsoft Excel ${ }^{\ominus}$. For the analysis and interpretation of safety culture dimensions, the methodology proposed by the Agency Healthcare Research and Quality (AHRQ) was applied. Results: The overall percentage of positive responses was $46 \%$, the dimension that showed a higher percentage of positive responses was "organizational learning and continuous improvement", however no dimension reached a value above $75 \%$. The dimension that showed the greatest fragility was a "non-punitive response to error" with the lowest percentage of positive responses (16\%). Most professionals (56\%) did not make any notification in the 12-month period. Regarding the participants' perception of patient safety in their work unit, a similar amount was observed among those who have a positive (very good and excellent) and negative (regular, bad and very bad) perception. Conclusions: The study reveals weaknesses in patient safety culture, highlighting the need to discuss the subject in all healthcare areas within the institution.
\end{abstract}

Key words: Patient safety; Safety Culture; Health Services; Evaluation; Quality of Care.

\title{
RESUMEN
}

Objetivo: Evaluar el nivel de cultura de seguridad del paciente, desde la perspectiva de los profesionales de la salud, en un hospital del sur de Brasil. Material y Método: Estudio cuantitativo que aplicó el instrumento Hospital Survey on Patient Safety Culture (HOSPSC), de mayo a junio de 2018; la muestra de 291 participantes se obtuvo por conveniencia, los datos se organizaron en Microsoft Excel ${ }^{\oplus}$. Para el análisis e interpretación de las dimensiones de la cultura de seguridad, se aplicó la metodología propuesta por la Agency Healthcare Research and Quality (AHRQ). Resultados: El porcentaje general de respuestas positivas fue del 46\%, la dimensión con mayor porcentaje de respuestas positivas fue "aprendizaje organizacional y la mejora continua"; ninguna dimensión alcanzó un valor superior al 75\%; la dimensión que mostró mayor fragilidad fue "respuesta no punitiva al error", con el porcentaje más bajo de respuestas positivas (16\%); la mayoría de los profesionales (56\%) no hicieron ninguna notificación en el período de 12 meses; con respecto a la percepción de los participantes sobre la seguridad del paciente en su unidad de trabajo, se observó una cantidad similar entre aquellos que tienen una percepción positiva (muy buena y excelente) y negativa (regular, mala y muy mala). Conclusiones: Existen debilidades en la cultura de seguridad del paciente, destacando la necesidad de discutir el tema en todos los ámbitos de atención de la institución.

Palabras clave: Seguridad del paciente; Cultura de seguridad; Servicios de salud; Evaluación; Calidad de atención.

Data de recepção: 30/07/2020

Data de aceitação: 03/03/2021 


\section{INTRODUÇÃO}

A segurança do paciente está diretamente relacionada com a qualidade nos serviços de saúde e é definida como a diminuição dos riscos desnecessários durante os processos assistenciais utilizando das melhores práticas para alcançar resultados, sem causar danos para o paciente ${ }^{(1,2)}$.

A cultura de segurança engloba a prevenção de agravos e a promoção à saúde por meio de atitudes e costumes que visam diminuir e/ou evitar riscos desnecessários ao paciente, através da identificação de comportamentos e dificuldades dos profissionais, promovendo espaços para transformaçóes, o que representa um processo complexo que tem como objetivo principal um cuidado seguro e efetivo ${ }^{(3,4)}$.

Existem diversos instrumentos ${ }^{(5,6)}$ que permitem avaliar a cultura de segurança de uma instituição, por meio da investigação dos elementos que influenciam de modo positivo e negativo a segurança dos pacientes. Estas informaçóes são essenciais para a tomada de decisóes e para o planejamento estratégico do serviço, uma vez que permitirá direcionar suas açóes com vistas a superação das limitaçóes encontradas ${ }^{(7)}$.

Hospitais de referência para o atendimento de especialidades possuem uma grande complexidade em seus processos assistenciais, sendo imprescindível a utilização de instrumentos que permitam reconhecer como a segurança do paciente está se apresentando, bem como as fragilidades e potencialidades presentes nestes processos que podem ser aprimorados em prol de maior qualidade da assistência oferecida aos pacientes.

Assim, propôs-se este estudo com o objetivo de avaliar o nível da cultura de segurança do paciente, sob a ótica de profissionais de saúde, em um hospital de grande porte na região Sul do Brasil. Como objetivos específicos: identificar as áreas de potencialidades em relação à cultura institucionais para a segurança do paciente e identificar áreas de fragilidades em relação à cultura de segurança neste hospital. A hipótese deste estudo é de que profissionais que atuam a um tempo maior na instituição e com maior experiência profissional, possuam uma percepção mais positiva em relação à segurança do paciente. Além disso, ao identificar as fragilidades e potencialidades em relação à cultura de segurança do paciente neste serviço, será possível o desenvolvimento de um plano estratégico para implementar práticas de assistência à saúde mais seguras.

\section{MATERIAL E MÉTODO}

Trata-se de um estudo quantitativo, com delineamento transversal, vinculado a um macroprojeto intitulado de "Segurança do paciente: construindo caminhos para cultura de segurança”, desenvolvido em um hospital de grande porte da regiāo Sul do Brasil, com aproximadamente 300 leitos, referência no atendimento de alta complexidade em várias áreas assistenciais. Este hospital possui um Núcleo de Segurança do Paciente (NSP), composto por uma equipe multiprofissional que desenvolve açóes voltadas para o cuidado seguro.

A amostra foi constituída por 291 participantes do total de 900 profissionais que atuam na instituição e foi obtida por conveniência, a partir do convite realizado a todos os participantes de uma ação educativa ofertada para todos os colaboradores do hospital.

Os critérios de elegibilidade foram: trabalhar na instituição no período mínimo 3 meses, ser maior de 18 anos e prestar carga horária mínima de $20 \mathrm{~h}$ semanais. Foram excluídos os que se encontravam em período de férias, licenças e/ou afastamentos.

Daqueles que aceitaram participar do estudo, não houve desistências portanto, não foram realizadas substituiçóes de participantes durante a coleta de dados entre os meses de maio a junho de 2018, oportunidade em que foi aplicado o instrumento Hospital Survey on Patient Safety Culture (HOSPSC), desenvolvido pela americana Agency Healthcare Research and Quality (AHRQ) em $2004^{(8)}$ e que foi traduzido e adaptado para o contexto brasileiro $^{(6)}$.

Os questionários foram autopreenchidos pelos colaboradores após a assinatura do termo de consentimento livre e esclarecido. $\mathrm{O}$ instrumento é composto por 50 questóes organizadas em doze sessóes que permitem a mensuração das múltiplas dimensóes da cultura de segurança do paciente, relacionadas a valores, crenças e normas institucionais, eventos adversos, comunicação, liderança e gestão ${ }^{(6)}$; além de informaçôes para caracterização da amostra, como o tempo em que o indivíduo trabalha na instituição, unidade ou área, 
a quantidade de horas de trabalho semanais, cargo e função assumida.

Os dados coletados foram digitados e organizados em planilhas eletrônicas do programa Microsoft Excel. A análise dos dados ocorreu por meio de estatística descritiva, a partir da metodologia proposta pela Agency for Healthcare Research and Quality ${ }^{(8)}$ e detalhado nos próximos três parágrafos:

Inicialmente os itens do instrumento HSOPSC foram avaliados por meio de uma escala Likert de cinco pontos, com categorias de respostas em grau de concordância ou a partir de uma escala de frequência. A escala de Likert está descrita como: 1. Concordo fortemente, 2. Concordo levemente, 3. Não concordo nem discordo, 4. Não concordo levemente e 5 . Não concordo fortemente. Os itens respondidos com a escala de frequência de cinco pontos: 1. Nunca, 2. Raramente, 3. As vezes, 4. Quase sempre e 5. Sempre.

A metodologia inclui ainda a combinação das duas categorias mais altas de resposta: "Concordo fortemente / Concordo, e na maioria das vezes / sempre", para os itens redigidos positivamente, e as duas categorias mais baixas de resposta: "Discordo fortemente / Discordo e Nunca / raramente", para itens redigidos negativamente, também chamados de reversos.

As dimensões que atingem pontuação de respostas positivas superior a $75 \%$ são classificadas como positivas, em relação a cultura segurança do paciente; a pontuaçáo entre 74 e $50 \%$ sáo consideradas neutras e abaixo de $50 \%$ são consideradas como negativas.

A análise dos dados foi através de estatística descritiva (valos absoluto, percentuais) e inferencial (teste qui-quadrado, $X^{2}$ ). Foi considerado um nível de significância $\mathrm{p}$ valor $\leq 0,05$ para um intervalo de confiança de $95 \%$.

Esta pesquisa seguiu os aspectos éticos estabelecidos pela Resolução CNS n 466/2012 do Brasil? ${ }^{(9)}$, sendo aprovado no Comitê de Ética em Pesquisa com Seres Humanos da Universidade Federal da Fronteira Sul, ano 2018 (Código: CAAE 85960518.0.0000.5564).

\section{RESULTADOS}

Entre os colaboradores profissionais houve predomínio da equipe de enfermagem, tanto entre os profissionais de nível superior quanto de nível médio representando $84 \%$ (244) dos sujeitos. Os profissionais de nível superior realizaram cursos de graduação em universidades, normalmente com carga horária a partir de 4.000 (quatro mil) horas de curso e quatro anos de duração, os profissionais de nível técnico são os que realizaram cursos profissionalizantes em escolas técnicas, com aproximadamente 1.800 (hum mil e oitocentas) horas de duração desenvolvidos em dois anos. A maioria dos profissionais, $83 \%$ (240), trabalham com uma carga horária entre 40 a 59 h por semana. $\mathrm{Na}$ Tabela 1 são apresentadas algumas características dos participantes.

$\mathrm{Na}$ Tabela 2 são descritas as características referentes à cultura de segurança do paciente, onde os scores de respostas positivas superiores a $75 \%$ são considerados áreas fortes para a segurança do paciente, resultados positivos que oscilam entre $75 \mathrm{e}$ $50 \%$ são considerados como área neutra, e abaixo de $50 \%$ são consideradas como áreas de frágeis, o que indica fragilidade no processo de trabalho.

Com relação à nota para a segurança do paciente na sua unidade segundo a percepção dos profissionais, observou-se um quantitativo semelhante entre os que têm uma percepçáo positiva (Excelente e Muito boa) e negativa (Regular, Ruim e Muito ruim), conforme o gráfico uno.

A Tabela 3 apresenta a associação entre as variáveis independentes e a Percepção sobre a segurança do paciente. O questionário específico da Percepçáo sobre a segurança do paciente foi respondido por 260 participantes, porém no momento de preencher o questionário, alguns participantes náo responderam o questionamento específico de uma das variáveis independentes (setor, categoria profissional, contato direto, tempo de trabalho, notificaçóes). Por isso, o teste estatístico foi realizado especificamente com o numero de participantes que tinha colocado a informação correspondente a variável específica. Assim, foi possível observar que houve diferença significativa na categoria profissional, contato direto e notificaçóes.

No Gráfico 5 apresenta-se o número de notificaçóes de incidentes e eventos adversos realizados pelos participantes nos últimos 12 meses. 
Tabela 1. Caracterizaçáo dos participantes. Chapecó-SC, Brasil, 2018, n= 291.

\begin{tabular}{|c|c|c|c|}
\hline Variável & & Fr & $\%$ \\
\hline \multirow[t]{3}{*}{ Categoria profissional } & Nível superior & 60 & $21 \%$ \\
\hline & Nível técnico & 217 & $74 \%$ \\
\hline & $\begin{array}{l}\text { Outros (auxiliar de enfermagem, recepcionista, auxiliar } \\
\text { de administraçáo e seguranças) }\end{array}$ & 14 & $5 \%$ \\
\hline \multirow[t]{8}{*}{ Cargo na Instituição } & Enfermeiro & 44 & $15 \%$ \\
\hline & Enfermeiro Trainee & 12 & $4 \%$ \\
\hline & Técnico Enfermagem & 189 & $65 \%$ \\
\hline & Administração/Direção & 6 & $2 \%$ \\
\hline & Recepcionista & 6 & $2 \%$ \\
\hline & Auxiliar de Serviço de Nutrição & 11 & $4 \%$ \\
\hline & Auxiliar equipe de Higienização/Hotelaria & 6 & $2 \%$ \\
\hline & Outros & 17 & $6 \%$ \\
\hline \multirow[t]{6}{*}{ Tempo de trabalho no hospital } & 3 meses - 1 ano & 38 & $13 \%$ \\
\hline & $1-5$ anos & 128 & $44 \%$ \\
\hline & $6-10$ anos & 58 & $20 \%$ \\
\hline & $11-15$ anos & 27 & $9 \%$ \\
\hline & $16-20$ anos & 20 & $7 \%$ \\
\hline & $>21$ anos & 20 & $7 \%$ \\
\hline \multirow[t]{6}{*}{ Tempo de trabalho no setor atual } & $<1$ ano & 67 & $23 \%$ \\
\hline & $1-5$ anos & 148 & $51 \%$ \\
\hline & $6-10$ anos & 46 & $16 \%$ \\
\hline & $11-15$ anos & 20 & $7 \%$ \\
\hline & $16-20$ anos & 7 & $2 \%$ \\
\hline & $>21$ anos & 3 & $1 \%$ \\
\hline \multirow[t]{2}{*}{ Tem contato direto com paciente } & Sim & 274 & $94 \%$ \\
\hline & Não & 17 & $6 \%$ \\
\hline
\end{tabular}

Tabela 2. Cultura de segurança do paciente por dimensôes, n=291. Chapecó-SC, Brasil, 2018.

\begin{tabular}{lccc}
\hline Dimensóes & Positivo & Neutro & Negativo \\
\hline 1. Expectativas e ações de promoção de segurança dos supervisores/gerentes. & $58 \%$ & $22 \%$ & $20 \%$ \\
2. Aprendizado organizacional e melhoria contínua. & $66 \%$ & $20 \%$ & $14 \%$ \\
3. Trabalho em equipe dentro das unidades. & $59 \%$ & $19 \%$ & $22 \%$ \\
4. Abertura da comunicação. & $48 \%$ & $21 \%$ & $31 \%$ \\
5. Retorno das informações e da comunicação sobre erro. & $60 \%$ & $18 \%$ & $22 \%$ \\
6. Respostas não punitiva ao erro. & $16 \%$ & $19 \%$ & $65 \%$ \\
7. Adequação de profissionais. & $34 \%$ & $24 \%$ & $42 \%$ \\
8. Apoio da gestão hospitalar para segurança do paciente. & $40 \%$ & $34 \%$ & $26 \%$ \\
9. Trabalho em equipe entre unidades. & $36 \%$ & $33 \%$ & $31 \%$ \\
10. Passagem de plantão / turno e transferências internas. & $44 \%$ & $26 \%$ & $30 \%$ \\
11. Percepção geral da segurança do paciente. & $41 \%$ & $24 \%$ & $35 \%$ \\
12. Frequência de eventos notificados. & $53 \%$ & $27 \%$ & $20 \%$ \\
\hline Índice geral de todas as dimensóes & $46 \%$ & $24 \%$ & $30 \%$ \\
\hline
\end{tabular}




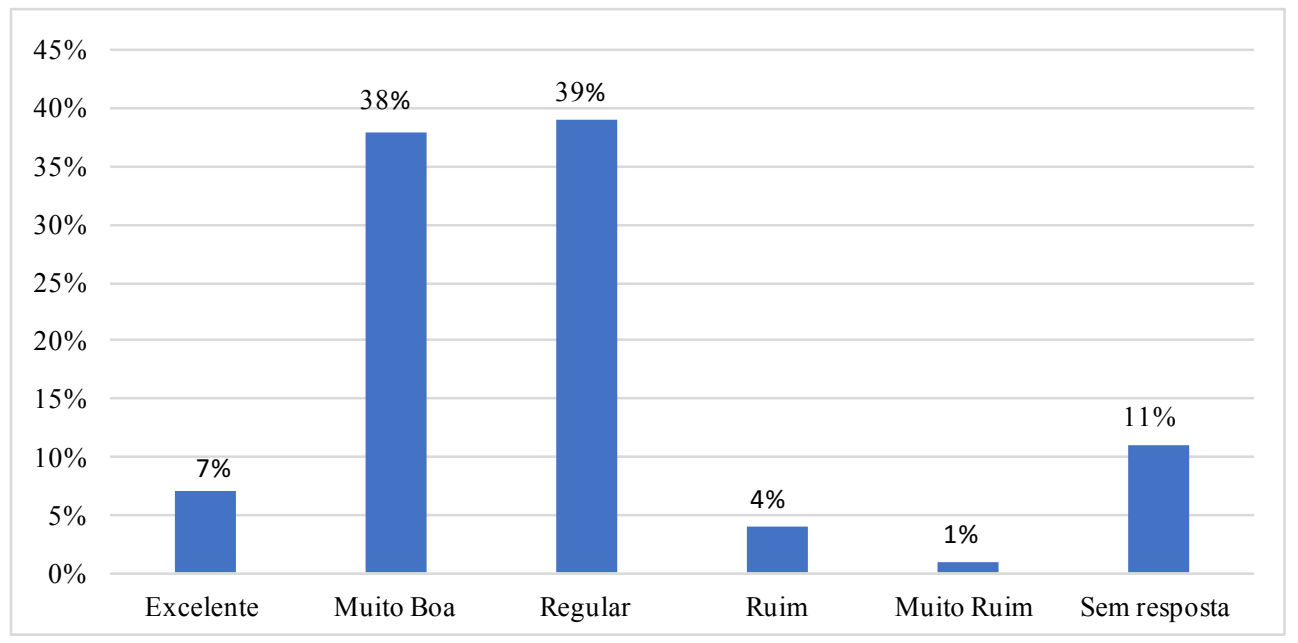

Gráfico 1. Percepção dos profissionais sobre a segurança do paciente na sua unidade, Chapecó-SC, Brasil, 2018.

Tabela 3. Associação entre as variáveis independentes e a Percepção sobre a segurança do paciente. Chapecó-SC, Brasil, $2018\left(\mathrm{n}=260^{*}\right)$.

\begin{tabular}{|c|c|c|c|c|c|c|}
\hline \multirow[b]{2}{*}{ Variável independentes } & & \multicolumn{3}{|c|}{$\begin{array}{c}\text { Percepçáo sobre segurança do paciente } \\
(\%)\end{array}$} & \multirow[b]{2}{*}{$X 2$} & \multirow[b]{2}{*}{$\mathbf{p}$} \\
\hline & & $\begin{array}{c}\text { Positiva (resposta } \\
\text { excelente e muito bom) }\end{array}$ & $\begin{array}{l}\text { Negativa (resposta } \\
\text { regular, ruim e } \\
\text { muito ruim) }\end{array}$ & Total & & \\
\hline \multirow[t]{3}{*}{ Setor } & Apoio & $31(47,0)$ & $35(53,0)$ & $66(25,9)$ & 0,846 & 0,655 \\
\hline & Aberta & $43(49,4)$ & $44(50,6)$ & $87(34,1)$ & & \\
\hline & Crítico & $55(53,9)$ & $47(46,1)$ & $102(40,0)$ & & \\
\hline \multirow[t]{3}{*}{ Categoria profissional } & Nível superior & $19(7,4)$ & $35(13,6)$ & $54(21,0)$ & 8,202 & 0,017 \\
\hline & Nível técnico & $108(42,0)$ & $86(33,5)$ & $194(75,5)$ & & \\
\hline & Outros & $3(1,2)$ & $6(2,3)$ & $9(3,5)$ & & \\
\hline \multirow[t]{2}{*}{ Contato direto } & Sim & $121(46,7)$ & $125(48,3)$ & $246(95,0)$ & 3,800 & 0,046 \\
\hline & Não & $10(3,9)$ & $3(1,2)$ & $13(5,0)$ & & \\
\hline \multirow[t]{3}{*}{ Tempo de trabalho } & Até 5 anos & $66(25,6)$ & $78(30,2)$ & $144(55,8)$ & 2,718 & 0,257 \\
\hline & 6 a 10 anos & $30(11,6)$ & $24(9,3)$ & $54(20,9)$ & & \\
\hline & 11 ou mais & $34(13,2)$ & $26(10,1)$ & $60(23,3)$ & & \\
\hline \multirow[t]{2}{*}{ Notificaçôes } & Não fez & $79(33,1)$ & $66(27,6)$ & $145(60,7)$ & 3,852 & 0,033 \\
\hline & $\mathrm{Fez}$ & $39(16,3)$ & $55(23,0)$ & $94(39,3)$ & & \\
\hline
\end{tabular}

* Número de participantes que responderam ao questionamento Percepção sobre a segurança do paciente. 


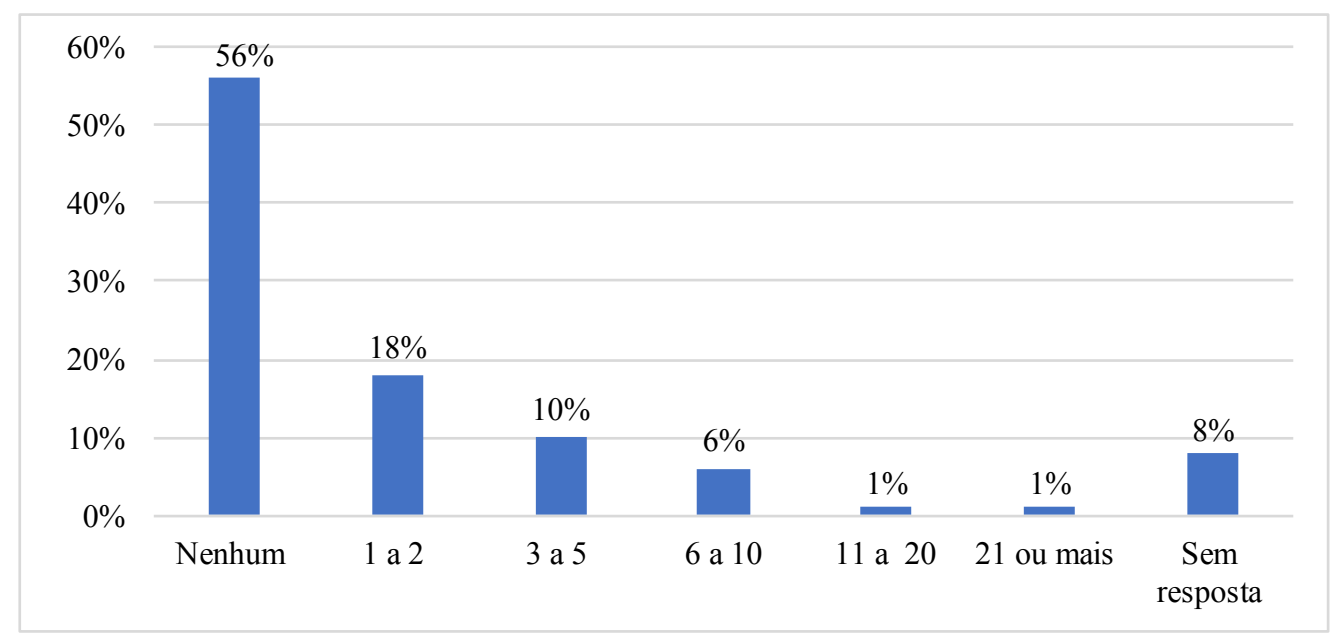

Gráfico 2. Número de notificações de incidentes e eventos adversos realizadas nos últimos 12 meses. Chapecó-SC, Brasil, 2018.

\section{DISCUSSÃO}

Os dados obtidos evidenciam a relação estabelecida entre eles e a complexidade da temática a ser discutida. Destaca-se que nenhuma das dimensóes atingiu o percentual de $75 \%$, o que é considerado área positiva de segurança do paciente, o que pode ser percebido como uma fragilidade. A dimensão "Resposta não punitiva ao erro" (16\%) apresentou o menor percentual de respostas positivas. Outro achado relevante é que a maioria dos profissionais (56\%) não realizou nenhuma notificação nos últimos 12 meses. Dentre as áreas consideradas neutras, destaca-se como potencialidades a dimensão "Aprendizado Organizacional e Melhoria Contínua" (66\%) e "Retorno das informações e da comunicação sobre erro" (60\%).

A equipe de enfermagem constitui a maior força de trabalho, a maioria dos participantes era da equipe de enfermagem, o que converge com outros estudos realizados na área. Isto está diretamente relacionado com essa categoria compor o maior quantitativo de pessoas das equipes de saúde ${ }^{(10-12)}$. No entanto, é preciso destacar que a cultura de segurança do paciente só é fortalecida quando todos os profissionais e setores da instituição estiverem engajados de forma igualitária na segurança do paciente ${ }^{(12)}$.

Este aspecto evidencia a necessidade de açóes também voltadas à sensibilização dos demais profissionais da instituição quanto ao envolvimento com a temática; além da educação permanente nos serviços, outro aspecto que deve fortalecer a cultura do cuidado seguro é a promoçáo de diálogos acerca do tema em todo o percurso formativo de trabalhadores da saúde, de modo que este seja o alicerce para sua atuação profissional futura.

Quase metade dos participantes referiu tempo de 1 a 5 anos tanto para atuação na instituição (44\%) quanto para a permanência em um único setor $(50 \%)$. Destaca-se que o período de atuação nos setores não condiz, necessariamente, com o tempo de trabalho do profissional na instituição. Ambos os períodos são considerados insuficientes para adaptação do profissional ${ }^{(13)}$.

Tais aspectos podem fragilizar a segurança dos pacientes, pois é sabido que os eventos adversos são mais frequentes com colaboradores não habituados a rotina do setor ou da instituição, visto que colaboradores mais antigos tendem a ter uma melhor percepção sobre situaçóes que podem gerar, de algum modo, prejuízo para o paciente ${ }^{(14,15)}$.

A permanência do colaborador em um único setor possibilita ainda o estabelecimento de vínculo com os colegas de trabalho e também com as principais condiçóes de saúde encontradas naquele espaço, possibilitando que este aprimore seus conhecimentos, competências e habilidades de 
acordo com as necessidades ali encontradas.

Com relação à Adequação do Quantitativo de Profissionais, para o trabalho desenvolvido, o índice de resposta positiva foi de $34 \%$, caracterizando zona negativa para segurança do paciente. A associação entre a falta de máo de obra qualificada e a carga horária de trabalho exaustiva dos profissionais tem forte influência para ocorrência de erros na assistência à saúde ${ }^{(16)}$. É necessário também correlacionar a sobrecarga de trabalho com a realização de registros de incidentes, tal aspecto contribui enfaticamente para o fenômeno da subnotificação ${ }^{(17)}$.

Nesse estudo, $55 \%$ dos profissionais não relataram nenhum evento adverso nos últimos 12 meses, semelhante a um estudo realizado na Arábia Saudita com 351 enfermeiros, em que 82,3\% também não realizaram nenhum comunicado ${ }^{(18)}$. Ambos os dados contradizem uma estimativa do Ministério da Saúde que aponta que 10\% de pacientes internados sofrerá algum evento adverso durante o período que estiver hospitalizado ${ }^{(19)}$, nesta perspectiva, cada profissional deveria ter realizado pelo menos uma notificação neste mesmo período.

Além da sobrecarga de trabalho supramencionada, são também possíveis justificativas para a não notificação ou subnotificação: relutância em declarar o próprio erro, falta de compreensão em como estruturar as notificaçóes, ausência de mudanças após a notificação ou até mesmo o medo de punições ou retaliação ${ }^{(13,20)}$. Este último vai de encontro aos achados na dimensão 6 , que se refere à "Resposta não punitiva ao erro".

Observou-se que o número de participantes que respondeu que não há uma Punição ao Erro é de $16 \%$, este índice caracteriza uma zona negativa para segurança do paciente, e ainda, alerta para um importante problema existente na cultura organizacional do serviço ${ }^{(13,21)}$.

Para mudar este cenário, as instituiçóes assim como os colaboradores, devem entender que as notificações não devem ser utilizadas como forma de punição, e sim como uma oportunidade de aprendizado e melhoria, pois a partir delas serão identificados processos de trabalho que precisam ser revisados ou reestruturados, bem como se trabalharão estratégias e formas que priorizem a segurança do paciente, minimizando a recorrência dos erros e aprimorando a qualidade da assistência ${ }^{(11,22)}$.

Na dimensão Frequência de Eventos Notificados que relaciona os possíveis problemas de segurança, eventos adversos e erros percebidos antes de chegar ao paciente, obteve-se um percentual de 53\% de respostas positivas, o que caracteriza zona neutra de segurança do paciente. Os participantes afirmaram que os erros sáo percebidos e corrigidos antes de afetar o paciente, no entanto, esses eventos acabam sendo subnotificados, o que também converge com o baixo número de notificaçóes.

Com relação à dimensão Expectativas e Ações de Promoção de Segurança dos Supervisores e Gerentes, obteve-se 58\% de respostas positivas, o que também caracteriza a zona neutra de segurança do paciente, ou seja, os profissionais percebem que seus superiores estão abertos para promover açóes de melhoria na segurança do paciente, mas ainda é uma área que precisa ser fortalecida na instituição, visto que a disponibilidade dos líderes para discutir sugestóes de melhoria para segurança do paciente torna o serviço mais agradável e colaborativo ${ }^{(6)}$.

Em contraposição, quando questionados com relação à dimensão Apoio da Gestão Hospitalar para Segurança do Paciente, o índice de resposta positiva foi de $40 \%$, ou seja, os profissionais têm dificuldade em observar as açóes dos gestores referente a segurança do paciente ${ }^{(6)}$.

Além disso, o dado sinaliza uma preocupação em virtude do papel fundamental dos gestores seja no planejamento estratégico para definição de objetivos ou no incentivo à equipe de saúde ao demonstrar interesse pela segurança do paciente. Alguns estudos demonstram que os maiores problemas relacionados à temática estão diretamente ligados ao não comprometimento desse pessoal ${ }^{(11,23)}$.

$\mathrm{Na}$ dimensão Abertura da Comunicação, a resposta positiva foi de $48 \%$, o que também se caracteriza como zona negativa para a cultura de segurança. Com isso percebe-se que os funcionários ainda têm receio em questionar os seus superiores e de falar sobre os erros que ocorrem na unidade. Isso ainda pode estar relacionado com a resposta não punitiva ao erro que é uma grande fragilidade dentro desta instituição, como supramencionado ${ }^{(24)}$.

A dimensão que trata sobre Trabalho em Equipe, verificou que $59 \%$ de respostas positivas, o que caracteriza zona neutra de segurança do paciente, conforme a metodologia proposta pela AHRQ. Esse achado se assemelha a um estudo realizado em dois municípios brasileiros, Imperatriz e Açailândia, em que colaboradores de enfermagem responderam 
um questionário de Atitudes de Segurança, sendo que a média para o Clima do Trabalho em Equipe ficou entre 63,43 e 54,67\%, respectivamente ${ }^{(25)}$.

Mesmo que haja uma relação de colaboração e respeito como demonstrado enfatiza-se a necessidade de estratégias que promovam, cada vez mais, comunicação assertiva e compartilhamento de conhecimentos em prol de um atendimento mais efetivo $^{(6)}$, aspectos que podem ser fortalecidos pela permanência dos profissionais no mesmo espaço de trabalho por um período de tempo que possibilite o estabelecimento de vínculo entre equipe, o que, de modo geral, não ocorre na instituição estudada.

Assim como o clima organizacional harmônico pode incentivar o trabalho em equipe por meio do apoio dos profissionais que aderem esse método de trabalho ${ }^{(26)}$ o contrário pode ser prejudicial à qualidade da assistência. Pode contribuir para a má comunicação entre colaboradores, por exemplo, as diferentes formaçóes profissionais que estabelecem relaçôes hierárquicas, que dificultam o diálogo e alertas sobre determinadas situaçóes que podem gerar riscos para os pacientes ${ }^{(14,27) \text {. }}$

Quanto ao Trabalho em Equipe entre os Setores ou Unidades, observa-se que o índice de respostas positivas foi de $36 \%$, caracterizando uma zona negativa para a cultura de segurança do paciente, destacando que a maioria dos profissionais identificam problemas neste processo, o que pode acarretar grandes prejuízos, já que o trabalho entre equipes é um fator importante para reduzir a taxa de erros, aumentar a segurança do paciente e amenizar a sobrecarga de trabalho ${ }^{(25,28,29)}$.

$\mathrm{O}$ índice para a dimensão Aprendizado Organizacional e Melhoria Contínua, foi de $66 \%$, considerada zona neutra para segurança do paciente, ou seja, a equipe consegue identificar momentos que precedem ou que ocorrem os erros, buscando ali uma oportunidade de aprendizagem. No entanto, esse dado contradiz o achado na dimensão 6 , que discute a resposta não punitiva ao erro $^{(6)}$. Algumas possibilidades surgem dessa contradição: alguns profissionais aprendem com incidentes sem reportar ao NSP, bem como há aqueles que identificam e fazem o relato, apenas verbalmente, para suas chefias diretas ${ }^{(24,30)}$.

Quando se supera a cultura punitiva ao erro e foca-se na aprendizagem, os funcionários, encorajados, passam a notificar mais, estimulados pela importância que o processo completo de notificaçáo tem para a segurança do paciente $\mathrm{e}$ qualidade da assistência ${ }^{(11)}$.

Quanto ao retorno das informaçóes e da comunicação sobre o erro, $60 \%$ das respostas foram positivas, caracterizando zona neutra para a cultura de segurança do paciente, indicando que o tema está presente na instituição em estudo, porém ainda precisa ser aprimorada para se tornar uma área positiva para a cultura de segurança. Estudos mostram que quando são tomadas medidas com base nas informações colhidas nas notificações, os funcionários também se sentem mais estimulados a fazerem os relatos de incidentes e eventos ${ }^{(30,31)}$.

Em relação à nota de Segurança do Paciente, verificou-se que os profissionais consideraram a segurança do paciente como muito boa (38\%) ou regular (39\%). Esses dados vâo ao encontro das respostas referentes dimensão sobre Percepção de Segurança do Paciente, evidenciando a necessidade de se trabalhar estratégias para fortalecer a cultura de segurança na instituiçâao ${ }^{(6,15)}$.

A segurança do paciente deve ser priorizada por todos os profissionais, independentemente se atende de forma direta ou indireta o paciente, enquanto que as instituiçóes devem desenvolver processos de trabalho seguros que minimizem ao máximo a possibilidade de erros ocorrerem. É preciso que além de seguir protocolos, o ambiente de trabalho também contribua para uma assistência segura $^{(6,32) \text {. }}$

De modo geral, o contexto apresentado demonstra que a segurança do paciente precisa ser aprimorada nesta instituição através do fortalecimento da cultura de segurança. Nesta direção, os achados deste estudo, especialmente as respostas que se apresentaram com índice negativo, podem ser tomadas como fonte primária de aprendizado e desenvolvimento da melhoria contínua na instituição ${ }^{(14)}$, reduzindo os fatores que contribuem para ocorrência de erros e potencializando açóes favorecem um cuidado seguro e de maior qualidade.

Embora os dados coletados possibilitem discussóes importantes na instituição e possam servir de base para planejamento e intervençóes referente a temática em outros locais, este estudo trata-se de uma experiência local e possui uma amostra discreta com relação ao número de profissionais que atuam na instituição pesquisada o que representa uma limitação para generalização dos resultados. Ainda, os dados coletados náo foram correlacionados com 
informaçôes relacionadas a estrutura institucional para segurança do paciente e do NSP, bem como as atividades por eles desenvolvidas, visto que não há dados sistematizados referentes a estes aspectos e que poderiam ser objetos de novas pesquisas relacionadas a temática.

\section{CONCLUSÓES}

Por meio da análise das dimensóes abordadas, foi evidenciado que existem fragilidades na cultura de segurança do paciente, destacando a necessidade de se discutir a temática em todas as esferas de atenção dentro da instituição. Destaca-se que há um aprendizado organizacional e melhoria contínua por se tratar da dimensão com maior índice percentual positivo, o que demonstra que já se tem um trabalho em andamento voltado para a cultura de segurança dentro da instituição.

\section{REFERÊNCIAS}

1. Romero MP, González RB, Calvo MSR, Fachado AA. A segurança do paciente, qualidade do atendimento e ética dos sistemas de saúde. Rev bioét [Internet]. 2018 [citado 2020 abr 15]; 26 (3): 333-42. Disponível em: https://www.scielo.br/pdf/ bioet/v26n3/1983-8042-bioet-26-03-0333.pdf.

2. Silva AT, Alves MG, Sanches RS, Terra FS, Resck ZMR. Assistência de enfermagem e o enfoque da segurança do paciente no cenário brasileiro. Saúde debate [Internet]. 2016 [citado $2020 \mathrm{abr}$ 15]; 40(111): 292-301. Disponível em: https:// www.scielo.br/pdf/sdeb/v40n111/0103-1104sdeb-40-111-0292.pdf.

3. Lagemann B, Abrantes MG, Baiense SN, Apratto PC, Gomes AR, Mello DRB. Problematizando o modelo de assistência biopsicossocial em saúde: Um relato de experiência. REINPEC [Internet]. 2018 [citado 2020 abr 15]; 4(1): 74-81. Disponível em: http://www.reinpec.org/reinpec/index.php/ reinpec/article/view/184/146.

4. Tondo JCA, Guirardello EB. Perception of nursing professionals on patient safety culture. Rev Bras Enferm [Internet]. 2017 [citado 2020 abr 16]; 70(6): 1284-90. Disponível em: https://
Um dos elementos que sobressaiu nos resultados relaciona-se à cultura náo punitiva ao erro, apresentando o menor índice percentual de respostas positivas, o que permite afirmar que os participantes acreditam que serão punidos mediante o erro cometido. É urgente que essa percepção seja transformada e desmistificada por meio de açôes que fortaleçam a cultura de segurança nas instituiçôes de saúde, e até mesmo a criação de sistemas que protejam os profissionais de retaliação ao relatarem um ambiente inseguro para o paciente.

É também essencial que as gerencias de saúde assumam uma postura de comprometimento incentivando as equipes a verbalizarem suas preocupaçóes relacionadas a segurança dos pacientes e dos próprios profissionais de saúde. Além disso, a formação de futuros profissionais de saúde deve promover espaços de diálogos referentes a atitudes seguras nos diferentes contextos de trabalho, focando na promoção e na prevenção de erros relacionados à assistência a saúde.

www.scielo.br/pdf/reben/v70n6/pt_0034-7167reben-70-06-1284.pdf.

5. Sexton JB, Helmreich RL, Neilands TB, Rowan K, Vella K, Boyden J, Roberts PR, Thomas EJ. The Safety Attitudes Questionnaire: psychometric properties, benchmarking data, and emerging research. BMC Health Services Research. [Internet] 2006 [citado 2020 abr 17]; 6(44): 1-10. Disponível em: https://link.springer.com/content/ pdf/10.1186/1472-6963-6-44.pdf.

6. Reis CT, Laguardia J, Vasconcelos AGG, Martins M. Reliability and validity of the Brazilian version of the Hospital Survey on Patient Safety Culture (HSOPSC): a pilot study. Cad Saúde Pública [Internet]. 2016 [citado $2020 \mathrm{abr}$ 16]; 32(11): 1-13. Disponível em: https://www.scielo.br/pdf/ csp/v32n11/1678-4464-csp-32-11-e00115614. pdf.

7. Magalhães FHL, Pereira ICA, Luiz RB, Barbosa $\mathrm{MH}$, Ferreira MBG. Clima de segurança do paciente em um hospital de ensino. Rev Gaúcha Enferm [Internet]. 2019 [citado 2020 abr 18]; 40(esp): e20180272. Disponível em: https://www. scielo.br/pdf/rgenf/v40nspe/1983-1447-rgenf-40spe-e20180272.pdf.

8. Sorra JS, Nieva VF. Hospital survey on patient safety culture. AHRQ Publication No. 04-0041. 
Rockville, MD: Agency for Healthcare Research and Quality; 2004.

9. Ministério da Saúde do Brasil. Resolução No 466, de 12 de dezembro de 2012. Aprovar as diretrizes e normas regulamentadoras de pesquisas envolvendo seres humanos [Internet]. Brasília: MS; 2012 [citado 2020 abr 18]. Disponível em: https://bvsms. saude.gov.br/bvs/saudelegis/cns/2013/res0466_12 12 2012.html

10. Boughaba A, Aberkane S, Fourar YO, Djebabra M. Study of safety culture in healthcare institutions: case of an Algerian hospital. Int J Health Care Qual Assur [Internet]. 2019 [citado 2020 abr 18]; 32(7): 1081-1097. Disponível em: https://pubmed.ncbi. nlm.nih.gov/31411092/.

11. Costa DB, Ramos D, Gabriel CS, Bernardes A. Cultura de segurança do paciente: avaliaçáo pelos profissionais de enfermagem. Texto Contexto Enferm [Internet]. 2018 [citado 2020 abr 18]; 27(3): e2670016. Disponível em: https://www. scielo.br/pdf/tce/v27n3/0104-0707-tce-2703-e2670016.pdf

12. Carvalho REFL, Arruda LP, Nascimento NKP, Sampaio RL, Cavalcante MLSN, Costa ACP. Assessment of the culture of safety in public hospitals in Brazil. Rev Latino-Am Enfermagem [Internet]. 2017 [citado 2020 abr 19]; 25:e2849. Disponível em: https://www.scielo.br/pdf/rlae/ v25/pt_0104-1169-rlae-25-e2849.pdf

13. Silva MVP, Carvalho PMG. Cultura de Segurança do paciente: atitudes dos profissionais de enfermagem de um serviço de pronto atendimento. $\mathrm{R}$ Interd [Internet]. 2016 [citado 2020 abr 19]; 9(1): 1-12. Disponível em: https://revistainterdisciplinar. uninovafapi.edu.br/index.php/revinter/article/ view/500/pdf_279

14. Tomazoni A, Rocha PK, Souza S, Anders JC, Malfussi HFC. Cultura de segurança do paciente em unidades de terapia intensiva neonatal: perspectivas da equipe de enfermagem e médica. Rev LatinoAm Enfermagem [Internet]. 2014 [citado 2020 abr 21]; 22(5): 755-63. Disponível em: https:// www.scielo.br/pdf/rlae/v22n5/pt_0104-1169rlae-22-05-00755.pdf

15. Kolankiewicz AC, Loro MM, Schmidt CR, Santos FP, Bandeira VA, Magnago TS. Patient safety climate among nursing staff: contributing factors. Acta Paul Enferm [Internet]; 2017 [citado 2020 abr 21]; 30(5): 531-7. Disponível em: https://www.scielo.br/pdf/ape/v30n5/0103-2100ape-30-05-0531.pdf

16. Carlesi KC, Padilha KG, Toffoletto MC, Henriquez-Roldán C, Canales MAJ. Patient Safety Incidents and Nursing Workload. Rev LatinoAm Enfermagem [Internet]. 2017 [citado 2020 abr 23]; 25: e2841. Disponível em: https://www. researchgate.net/publication/316030171_Patient_ Safety_Incidents_and_Nursing_Workload

17. Fagerstrom L, Kinnunen M, Saarela J. Nursing workload, patient safety incidents and mortality: an observational study from Finland. BMJ Open [Internet]. 2018 [citado 2020 abr 23]; 8: e016367. Disponível em: https://bmjopen.bmj.com/content/ bmjopen/8/4/e016367.full.pdf

18. Alquwez N, Cruz JP, Almoghairi AM, Al-otaibi RS, Almutairi KO, Alicante JG, et al. Nurses' Perceptions of Patient Safety Culture in Three Hospitals in Saudi Arabia. Journal of Nursing Scholarship. [Internet] 2018 [citado 2020 abr 25]; 50(4): 1-10. Disponível em: https://doi.org/10.1111/jnu.12394

19. Ministério da Saúde Brasil. Agência Nacional de Vigilância Sanitária-ANVISA. Documento de referência para o Programa Nacional de Segurança do Paciente. [Internet]. Brasil: ANVISA. 2014 [citado 2020 abr 25]; 40 p. Disponível em: https:// bvsms.saude.gov.br/bvs/publicacoes/documento_ referencia_programa_nacional_seguranca.pdf.

20. Cole DA, Bersick E, Skarbek A, Cummins K, Dugan K, Grantoza R. The courage to speak out: A study describing nurses' attitudes to report unsafe practices in patient care. J Nurs Manag [Internet]. 2019 [citado 2020 abr 26]; 00: 1-6. Disponível em: https://onlinelibrary.wiley.com/doi/abs/10.1111/ jonm.12789

21. Ministério da Saúde Brasil. Agência Nacional de Vigilância Sanitária-ANVISA. Assistência segura: uma reflexão teórica aplicada à prática [Internet]. Brasil: ANVISA. 2017 [citado $2010 \mathrm{abr}$ 26]; 168 p. Disponível em: https://www.gov.br/ anvisa/pt-br/centraisdeconteudo/publicacoes/ servicosdesaude/publicacoes/publicacoes/caderno1 -assistencia-segura-uma-reflexao-teorica-aplicadaa-pratica.pdf/view

22. Sartor GD, Da Silva BF, Masiero AV. Segurança do paciente em hospitais de grande porte: panorama e desafios. Cogitare Enferm [Internet]. 2016 [citado 2020 abr 28]; 21 n. esp: 01-08. Disponível em: https://revistas.ufpr.br/cogitare/article/view/ 45644/pdf

23. Minuzzi AP, Salum NC, Locks MOH. Assessment of patient safety culture in intensive care from the health team's perspective. Texto Contexto Enferm [Internet]. 2016 [citado 2020 abr 29]; 25(2): e1610015. Disponível em: https://www.scielo.br/ pdf/tce/v25n2/0104-0707-tce-25-02-1610015. pdf

24. Lemos GC, Azevedo C, Bernardes MFVG, Ribeiro HCTC, Menezes AC, Mata LRF. A cultura de segurança do paciente no âmbito da enfermagem: Reflexão teórica. RECOM [Internet]. 2018 
[citado 2020 abr 30]; 8: e2600. Disponível em: http://seer.ufsj.edu.br/index.php/recom/article/ view/2600/1880

25. França ACS, Firmo WCA, Pinto WML, Moura MÊS. Avaliação do clima de segurança do paciente entre profissionais de enfermagem. Cienc enferm [Internet]. 2020 [citado 2020 jul 15]; 26:7. Disponível em: http://dx.doi.org/10.4067/s071795532020000100206

26. Santiago THR, Turrini RNT. Cultura e clima organizacional para segurança do paciente em Unidades de Terapia Intensiva. Rev Esc Enferm USP [Internet]. 2015 [citado 2020 mai 2]; 49(Esp): 123-130. Disponível em: https://www. scielo.br/pdf/reeusp/v49nspe/1980-220X-reeusp49-spe-0123.pdf

27. Nogueira JWS, Rodrigues MCS. Comunicação efetiva no trabalho em equipe em saúde: desafio para a segurança do paciente. Cogitare Enferm [Internet]. 2015 [citado 2020 mai 2]; 20(3): 636-640. Disponível em: https://revistas.ufpr.br/ cogitare/article/view/40016/26245

28. Bohrer CD, Marques LGS, Vasconcelos RO, Oliveira JLC, Nicola AL, Kawamoto AM. Comunicação e cultura de segurança do paciente no ambiente hospitalar: visão da equipe multiprofissional. Rev Enferm UFSM [Internet]. 2016 [citado 2020 mai 3]; 6(1): 50-60. Disponível em: https://periodicos. ufsm.br/reufsm/article/view/19260/pdf_1

29. Souza CS, Tomaschewski-Barlem JG, Rocha LP, Barlem ELD, Silva TL, Neutzling BRS. Cultura de segurança em unidades de terapia intensiva: perspectiva dos profissionais de saúde. Rev Gaúcha Enferm [Internet]. 2019 [citado 2020 mai 3] 40(esp): e20180294. Disponível em: https://www. scielo.br/pdf/rgenf/v40nspe/1983-1447-rgenf-40spe-e20180294.pdf

30. Siman AG, Brito MJM. Mudanças na prática de enfermagem para melhorar a segurança do paciente. Rev Gaúcha Enferm [Internet]. 2016 [citado 2020 mai 3]; 37(esp): e68271. Disponível em: https:// www.scielo.br/pdf/rgenf/v37nspe/0102-6933rgenf-1983-14472016esp68271.pdf

31. Ferezin TPM, Ramos D, Caldana G, Gabriel CS, Bernardes A. Analysis of adverse event reporting at accredited hospitals. Cogitare Enferm [Internet]. 2017 [citado 2020 mai 3]; 22(2): 1-8. Disponível em: https://pdfs.semanticscholar.org/deb4/b1d9c1 c838254f856c7781b9542187f6a2ff.pdf

32. Biasibetti C, Hoffmann LM, Rodrigues FA, Wegner W, Rocha PK. Comunicação para a segurança do paciente em internaçôes pediátricas. Rev Gaúcha Enferm [Internet]. 2019 [citado 2020 mai 4]; 40 (esp): e20180337. Disponível em: https://www. scielo.br/pdf/rgenf/v40nspe/1983-1447-rgenf-40spe-e20180337.pdf 